\title{
Cardiac surgical outcomes in abdominal solid organ (renal and hepatic) transplant recipients: a case-matched study
}

\author{
Rajiv Sharma ${ }^{a, *}$, Carmel Hawley $^{b}$, Raylene Griffin ${ }^{a}$, Julie Mundy ${ }^{a}$, Paul Peters ${ }^{a}$ and Pallav Shah \\ a Department of Cardiothoracic Surgery, Princess Alexandra Hospital, Brisbane, Australia \\ b Department of Nephrology, Princess Alexandra Hospital, Brisbane, Australia \\ * Corresponding author. Princess Alexandra Hospital, Woolloongabba, Brisbane, QLD 4102, Australia. Tel: +61-07-31767675; fax: +61-07-31766954; \\ e-mail: docrajivsharma@gmail.com (R. Sharma).
}

Received 10 February 2012; received in revised form 13 May 2012; accepted 24 May 2012

\begin{abstract}
OBJECTIVES: This study aims to investigate the outcomes of cardiac surgery in patients with abdominal solid organ transplants and to compare them with the case-matched population undergoing cardiac surgery.

METHODS: Data from all transplant recipients abdominal solid organ transplant (ASOT) $N=36$ (30 renal and 6 hepatic) who underwent cardiac surgery in a single centre during the period from January 1997 to December 2010 were collected from hospital transplant registries and the cardiac database. The transplant recipients were case matched (CM) with 104 patients in terms of the variables of age, sex and the type of cardiac surgery. Follow-up data were obtained from medical records and by a set of questionnaire through telephonic interviews.

RESULTS: Follow-up times were $4.5 \pm 3.2$ and $3.9 \pm 3.2$ years in the transplant and CM groups, respectively. Follow-up in the transplant group was $100 \%$. There was no 30 -day mortality in the transplant group. Thirty-day combined major morbidities were $9 \%$ in the matched group vs $11 \%$ in the transplant patients $(P=0.6)$. Median length of stay was 6 days (inter-quartile range, IQR 5.9) for ASOT vs 5 days (IQR 4.6) for $\mathrm{CM}(P<0.01)$. New dialysis was $8.3 \%$ in transplant patients compared with $0.96 \%$ in the matched population, while infection was 16.66 vs $0.42 \%$ in the $\mathrm{CM}$ cohort. There was no allograft failure/dysfunction at the time of death or latest follow-up. Late deaths were 8 of $36(22 \%)$ in ASOT vs 6 of $104(6 \%)$ in CM. Infection (63\%) was the most frequent major cause of death in transplant patients. One-, 2-, 5and 10-year survivals for ASOT vs CM were $94,88,80,59$ vs $99,99,91,85 \%$, respectively. Multivariate predictors of mortality were increasing age (hazard ratio, HR 1.1, 95\% confidence interval, $\mathrm{Cl} 1.04-1.18 ; \mathrm{P}=0.003)$ and solid organ transplantation $(\mathrm{HR} 3.44, \mathrm{Cl}$ $1.19-9.98 ; P=0.023)$.
\end{abstract}

CONCLUSIONS: Cardiac surgery can be performed in patients with abdominal solid organ tranpslant recipients with acceptable early morbidity and mortality. However, long-term survival in transplant patients is poor. Infection remains the most common cause of death.

Keywords: Renal transplantation • Liver transplantation • Organ transplantation • Cardiac surgical procedures/mortality

\section{INTRODUCTION}

A rapid improvement in transplant medicine in the last few decades has seen more people receiving transplants. Transplant patients innately have an increased burden of co-morbidities per se. The milieu interior is further deleteriously affected by altered immune status and the multitude of drugs administered to them. Consequently, it is not surprising that the relative risk of cardiovascular events and the absolute risk of cardiovascular death are increased in allograft recipients compared with the agematched population without transplants [1]. However, despite their increasing age and higher risk profile, excellent early survival has been reported in both hepatic [2] and renal [3] transplant recipients. This ever-expanding cohort has a unique course of pathophysiological events. Cardiopulmonary bypass is deleterious to even the native organs by virtue of not being physiological, therefore, it would also adversely affect the transplanted organs when they are exposed to cardiopulmonary bypass during cardiac surgery. In addition, the altered post-transplant physiology (e.g. by immunosuppression) would affect the cardiac surgical outcomes. Consequently, it has become important to study the course of existing cardiovascular disease and the evolution and progress of new cardiovascular disease in solid organ transplant recipients and to study the effect of disease management algorithms on the allografts, compared with the general population undergoing cardiac surgery. The new set of problems arising from this surrogate disease poses interesting and hitherto unanswered questions.

This is the first study addressing the short- and long-term outcomes of cardiac surgery in solid organ transplant recipients in terms of comparative analysis with a case-matched (CM) population undergoing cardiac surgery. It aims to address the abovementioned issues in an effort to modify treatment, guide informed consent, help in resource allocation and give directions in future health policy planning. 


\section{MATERIALS AND METHODS}

The study was approved by the institutional ethics committee. All patients who had renal or hepatic transplant in our and other hospitals and went on to have cardiac surgery at our university hospital were included in our study. This comprised patients receiving allografts from 1984 to December 2010 abdominal solid organ transplant (ASOT). Each of these patients were CM in a ratio of 1:3 for the variables of age, sex and the type of operation performed.

Data were collected in a prospective manner from the separate renal and hepatic transplant registries of the hospital.

\section{Demographic, cardiac, renal and hepatic variables}

The cardiac surgical database provided preoperative information of patient demographics. Data were collected for the patient age at the time of cardiac surgery, gender and preoperative morbidities, e.g. diabetes, hypertension, history of smoking, family history, dyslipidaemia, cerebrovascular disease, peripheral vascular disease and chronic obstructive pulmonary disease (COPD). Following this, the severity of cardiovascular disease was risk stratified by using logistic EuroSCORE. Cardiovascular variables like angina, dyspnoea, New York Heart Association (NYHA) and Canadian Cardiovascular Society class at the time of cardiac surgery and follow-up, previous myocardial infarction and previous cardiac intervention were recorded. Clinical history including any change in the cardiovascular drug regimen during cardiac surgery and routine laboratory test values were recorded.

Specific data regarding transplant surgery, e.g. reason for transplant of particular organ, type of transplant viz. cadaveric or live donor, type of immunosuppressant, change of immunosuppression regimen in the cardiac surgical perioperative period, the duration of immunosuppression and complete allograft follow-up data were obtained from specific records kept in the renal and hepatic transplant facilities and the transplant registries.

The operative data were collected detailing various procedures, type of conduits and valve prosthesis, cardiopulmonary bypass and cross-clamp times, previous cardiovascular interventions and repeat cardiovascular interventions.

Patients. The study period spanned 13 years from January 1997 to December 2010. All patients who underwent cardiac surgery in our hospital after receiving allograft in our hospital or elsewhere $(N=36)$ were included in the study. This formed the transplant group, 30 renal transplant patients (83.4\%) formed Group I, while 6 hepatic transplant patients (16.6\%) comprised Group II. Together, they added up to a total of 36 transplant patients comprising Group III. The CM population of 104 patients formed Group IV. These 36 patients were CM with the variables of age, sex and type of cardiac surgery. This comprised the CM group $(N=104)$. One patient who had aortic and tricuspid valve repair with coronary artery bypass graft surgery could not be $\mathrm{CM}$, thereby explaining the discrepancy in the number of the CM cohort (Table 1).

Operative procedure. All procedures were done on cardiopulmonary bypass using blood cardioplegia except four in the transplant group (one pericardiectomy and three off-pump left internal thoracic artery-left anterior descending artery). In all patients operated on cardiopulmonary bypass, the perfusion pressures were kept at a mean of $75-80 \mathrm{mmHg}$ aiming at perfusing the allograft optimally and keeping an adequate safety margin in perfusion should the perfusion pressures fall in any eventuality.

Antibiotic prophylaxis. Antibiotic prophylaxis was given as per the unit protocol with thrice daily doses of cephazolin starting at induction and continued to the first postoperative day. However, patients with endocarditis received antibiotics as indicated by the blood cultures. Infectious disease physicians were consulted for advice regarding antibiotic usage where appropriate.

Immunosuppression. All patients except 4 were on immunosuppression, even those with failed transplants. According to the cardiothoracic and transplant team's protocol, no change in immunosuppression was effected; however, all patients received $100 \mathrm{mg}$ of hydrocortisone as a stress dose immediately after induction, but none postoperatively. No $\mathrm{CM}$ patient was on immunosuppression for any reason. The preoperative immunosuppression was restarted as soon as possible postoperatively, on resumption of oral intake or through a nasogastric tube.

Monitoring of allograft function. In the perioperative period, routine investigations were carried out. Routinely, full blood counts, coagulation profile, urea, creatinine, serum sodium, potassium, chloride and magnesium levels and liver enzymes viz. aspartate aminotransferase, alanine aminotransferase, gammaglutamine transferase and alkaline phosphatase (ALP) on Day 0,1 , 2 and Day 4 were measured. If the patients stayed more than 5 days another set of tests were performed immediately before

Table 1: Type of cardiac surgery in four groups

\begin{tabular}{|c|c|c|c|c|c|c|}
\hline & $\begin{array}{l}\text { Group } 1 \text { renal } \\
\text { transplant recipients } \\
(N=30)(\%)\end{array}$ & $\begin{array}{l}\text { Group } 2 \text { hepatic } \\
\text { transplant recipients } \\
(N=6)(\%)\end{array}$ & $\begin{array}{l}\text { Group } 3 \text { all } \\
\text { organ recipients } \\
(N=36)(\%)\end{array}$ & $\begin{array}{l}\text { Group } 4 \text { matched } \\
\text { cohort-non-transplant } \\
(N=104)(\%)\end{array}$ & $\begin{array}{l}P \text {-value all } \\
\text { groups }\end{array}$ & $\begin{array}{l}P \text {-value } \\
\text { Group } \\
3 \text { vs } 4\end{array}$ \\
\hline CABG & $15(50)$ & $3(50)$ & $18(50)$ & $51(49)$ & \multirow[t]{4}{*}{0.99} & \multirow[t]{4}{*}{0.98} \\
\hline $\begin{array}{l}\text { Valve replacement/ } \\
\text { repair }\end{array}$ & 7 (17) & 1 (17) & $8(22.2)$ & $26(25)$ & & \\
\hline $\begin{array}{l}\text { Both valve surgery/ } \\
\text { CABG }\end{array}$ & $6(20)$ & $1(17)$ & $7(19.4)$ & $18(17)$ & & \\
\hline Others & $2(7)$ & 1 (17) & $3(8.3)$ & $9(9)$ & & \\
\hline
\end{tabular}

$P=0.99$ comparing differences between all groups (Fisher's exact test). CABG: coronary artery bypass graft. 
discharge. Strict intake and output balance were maintained. The transplant medicine team was involved in the clinical management of the transplant cohort where appropriate.

Discharge. All patients were discharged home in routine practice. Patients requiring rehab or input from other medical teams continued to be under the primary care of the surgical team.

\section{Outcomes variables}

Postoperative information comprised, but was not limited to, 30-day (in-hospital) morbidity and mortality viz., it also included the use of blood products, ventilation data, new renal failure, readmission for cardiovascular or transplant organ dysfunction etc. The details about the renal and hepatic dysfunction at the time of cardiac surgery including their creatinine and urea levels and the hepatic enzyme levels were derived from this database and were then counter-checked from the renal and hepatic transplant registries.

Patients' follow-up for both the transplant and CM groups was completed by medical records including the most recent outpatient clinic visit and was supplemented by the chronology of general practice letters. Finally, each patient was contacted and the follow-up data were cross-checked and supplemented by a set of questionnaire through telephone interviews.

\section{Statistical analysis}

Descriptive statistics used for continuous variables were mean and standard deviation or median with inter-quartile range (IQR) depending on data distribution. Categorical variables were described with absolute numbers and percentages. For univariate comparisons between treatment groups, $\chi^{2}$ test, Fisher's exact test, unpaired $t$-test and Wilcoxon rank-sum test were used where appropriate. Kaplan-Meier survival methods and log-rank test were used for survival analyses.

For multivariate comparisons between treatment groups, binary logistics regression and Cox proportional hazard methods were used. Indices of cardiac and functional status (logistic EuroSCORE, NYHA grade, past myocardial infarction, presence of current angina, left ventricular ejection fraction etc.) were included as covariates in multivariate models. For logistic models, odds ratio and $95 \%$ confidence interval $(95 \% \mathrm{Cl})$ are described. For survival methods, hazard ratio (HR) and $95 \% \mathrm{Cl}$ are described. All $P$-values were two-sided, and a $P$-value of $<0.05$ was considered significant $a$ priori.

\section{RESULTS}

\section{Demographics}

Of all the variables studied in demographics, hypertension was more prevalent in the transplant group 74.85 vs $63.5 \%(P=0.05)$, and renal transplant patients were more hypertensive than liver transplant patients (83 vs $66.7 \%$ ). Transplant patients were also more likely to be smokers with either current or previous history of smoking $(P=0.03)$. The rest of the variables were comparable between all groups (Table 2 ).

\section{Risk factors for cardiac surgery}

The median (IQR) of the EuroSCORE was comparable between all groups $(P=0.08)$, but was higher in the transplant recipients when compared with CM $(P=0.045)$. The comparison of the EuroSCORE distribution between Groups III and IV showed low (25 vs 37.5\%), medium (38.9 vs $37.5 \%$ ) and high risks ( 36.1 vs $25 \%$ ), respectively

Table 2: Demographics and risk factors for cardiac surgery

\begin{tabular}{|c|c|c|c|c|c|c|}
\hline $\begin{array}{l}\text { Demographic } \\
\text { variables }\end{array}$ & $\begin{array}{l}\text { Group } 1 \text { renal } \\
\text { transplant recipients } \\
(N=30)\end{array}$ & $\begin{array}{l}\text { Group } 2 \text { hepatic } \\
\text { transplant recipients } \\
(N=6)\end{array}$ & $\begin{array}{l}\text { Group } 3 \text { all organ } \\
\text { recipients }(N=36)\end{array}$ & $\begin{array}{l}\text { Group } 4 \text { matched cohort- } \\
\text { non-transplant }(N=104)\end{array}$ & $\begin{array}{l}P \text {-value all } \\
\text { groups }\end{array}$ & $\begin{array}{l}P \text {-value } \\
\text { Group } 3 \text { vs } \\
4\end{array}$ \\
\hline Age (years) & $55.7 \pm 11.5$ & $60.7 \pm 8.0$ & $56.5 \pm 11.0$ & $56.5 \pm 11.1$ & 0.65 & 0.94 \\
\hline Gender (male), $N(\%)$ & $22(73 \%)$ & $5(83 \%)$ & $27(75 \%)$ & $78(75 \%)$ & 0.93 & 1.0 \\
\hline Hypertension, N (\%) & $25(83 \%)$ & $4(66.7 \%)$ & $29(80.6 \%)$ & $65(62.5 \%)$ & 0.08 & 0.05 \\
\hline Diabetes & $9(30 \%)$ & $0(0 \%)$ & $6 / 35(25 \%)$ & $25(24 \%)$ & 0.60 & 0.55 \\
\hline Dyslipidaemia & $20(66.7 \%)$ & $2(33.3 \%)$ & $22(61.1 \%)$ & $72(69.2 \%)$ & 0.19 & 0.37 \\
\hline Smoking & & & & & & 0.03 \\
\hline Non-smoker & $12(40 \%)$ & $3(50 \%)$ & 15 (41.7\%) & $40(38.5 \%)$ & 0.092 & \\
\hline Former & $18(60 \%)$ & $3(50 \%)$ & $21(58.3 \%)$ & 47 (45.2\%) & & \\
\hline Current & 0 & 0 & 0 & $17(16.3 \%)$ & & \\
\hline $\begin{array}{l}\text { Family history of } \\
\text { coronary disease }\end{array}$ & $8(26.7 \%)$ & $1(16.7 \%)$ & $9(25 \%)$ & $42(40.4 \%)$ & 0.23 & 0.10 \\
\hline History of CVA/TIA & $\begin{array}{l}3 \text { (10\%); ( } 2 \text { TIA, } 1 \\
\text { CVA) }\end{array}$ & $0(0 \%)$ & $3(8.3 \%)$ & 8 (7.7\%); (3 TIA, 5 CVA) & 0.32 & 0.90 \\
\hline $\begin{array}{l}\text { Peripheral vascular } \\
\text { disease }\end{array}$ & $4(13.3 \%)$ & $1(16.7 \%)$ & $5(13.9 \%)$ & $8(7.8 \%)$ & 0.35 & 0.27 \\
\hline $\begin{array}{l}\text { Respiratory disease } \\
\text { (COPD) }\end{array}$ & $6(20 \%)$ & $0(0 \%)$ & $6(16.7 \%)$ & $14(13.5 \%)$ & 0.51 & 0.64 \\
\hline Previous MI & $6(20.7 \%)$ & $2(33.3 \%)$ & $8(25.2 \%)$ & 20 (19.2\%) & 0.70 & 0.64 \\
\hline
\end{tabular}

All P-values relate to comparison between characteristics of Groups 1,2 and 4. COPD: chronic obstructive pulmonary disease; CVA: cerebrovascular accident; TIA: transient ischaemic attack; MI: myocardial infarction. 
with $P$-values of 0.27 in all group comparison, while the $P$-value was 0.30 between Groups III and IV.

Clinical risk factors that are known to increase mortality and morbidity in cardiac surgery patients viz. peripheral vascular disease, unstable angina, left main disease; congestive cardiac failure and decreased ejection function were comparable among the various groups and between Groups III and IV (Table 2).

\section{Renal and hepatic variables}

Transplant variables. The most common reason for renal transplant was glomerulonephritis (46.7\%) followed by reflux nephropathy (23.4\%) and polycystic kidney disease (10\%). systemic lupus erythematosus, lead toxicity, diabetes and light-chain nephropathy were other culprits. Cirrhosis was the most common cause of hepatic transplant (33.3\%). Other causes werehepatocellular carcinoma, alcoholic liver disease, cholangitis and non steroidal analgesic drug hepatopathy. Of the 30 renal transplant patients, 5 were transplanted twice, while 2 were transplanted thrice. All the liver transplant patients received a transplant only once.

Other renal and hepatic variables. Three patients with renal transplants were on dialysis ( 2 haemodialysis and 1 peritoneal dialysis), preoperatively. No patient in the hepatic transplant group was on dialysis. However, in the case-matched group only, 1 patient was on preoperative dialysis.

Renal and hepatic functions. The perioperative renal functions are depicted in Fig. 1a. As expected, there was a transient allograft dysfunction after cardiopulmonary bypass as demonstrated by the creatinine trends. Similarly, there was a trend towards transient allograft dysfunction in the liver transplant patients (Fig. $1 \mathrm{~b}$ and c). However, the elevated enzyme levels normalized or tended to normalize to base line levels at discharge. The elevation of liver enzymes in the CM population was absent, but transient elevation of creatinine seen in the CM population was insignificant.

(a)

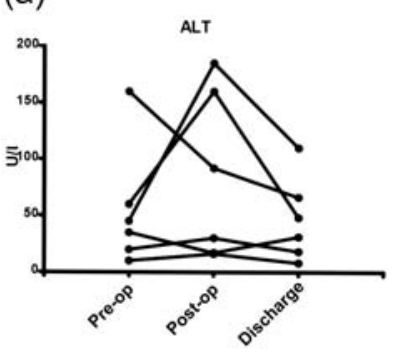

(b)

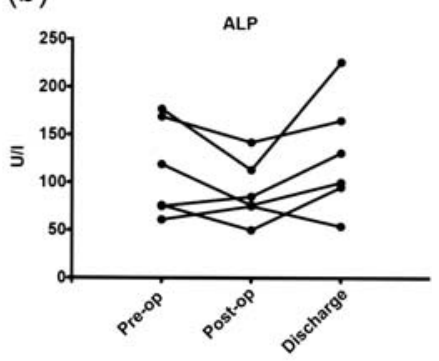

(c)

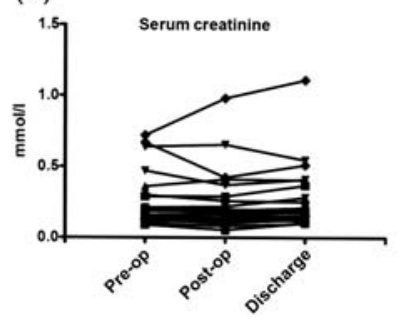

Figure 1: (a) Perioperative trends of alanine transaminase in liver transplant patients. (b) Perioperative trends of alkaline phosphatase in liver transplant patients. (c) Perioperative trends of creatinine in renal transplant patients.
Cardiac surgery variables. coronary artery bypass graft (CABG) constituted $50 \%$ of patients in the transplant group, and $49 \%$ in the CM group. Valve repair or replacement comprised 22.2 and $25 \%$ patients in the transplant and CM groups, respectively. Similarly, patients with both valve and coronary surgery were 19.4 and $17 \%$ in the transplant and control, respectively. The other surgery cohorts had 8.3 and $9 \%$ patients in the transplant and $\mathrm{CM}$ groups, respectively. The $P$-value between the groups was 0.98. Two patients with renal transplants had redo cardiac surgeries.

Average time from transplant to cardiac surgery was $10.8 \pm 7.4$ and $4.2 \pm 3.0$ years in the renal transplant and liver transplant patients, respectively, while the time from cardiac surgery to follow-up was 46.3 (IQR = 20.8-84.1) and 38.9 months (IQR = 14.6$72.3)$ in the transplant and $C M$ population, respectively $(P=0.25$, Table 3).

The cardiopulmonary bypass time in minutes in the transplant group was 67.5 (49.5-120) and in the CM population it was 81.5 (61-110.5) $(P=0.11)$. Similarly, the cross-clamp times were 44 (28-68.5) minutes in the ASOT cohort and 57.5 (40-81.5) minutes in the CM cohort $(P=0.07)$. In 4 patients of the transplant group, cardiopulmonary bypass was not used either because it was not needed, e.g. in pericardiectomy, or the operation was done off-pump. LITA was used in 16 patients of the transplant group and 60 in the CM group.

Outcomes data. Follow-up was complete in $100 \%$ of the surviving transplant group. The follow-up in the cross-matched group was done in 94 (90.38\%) patients. Four of the 10 (9.62\%) patients not included in the follow-up in the matched group did not participate.

The follow-up time was $1649 \pm 1176$ ( $4.5 \pm 3.2$ years) and $1428 \pm 1173$ days $(3.9 \pm 3.2$ years $)$ in the transplant cohort and CM population, respectively (Table 3 ).

Significant morbidities are as outlined in Table 4. There was no loss of allograft function in the transplant group, although dialysis was required in $3(8.3 \%)$ patients in the transplant group and in $1(0.96 \%)$ in the cross-matched population $(P=0.049)$. The patients requiring dialysis recovered their allograft function before discharge. The rate of all infection was $6(16.66 \%)$ and 6 $(0.42 \%)$ in the ASOT and the CM groups, respectively $(P=0.045)$. There were 3 patients with leg wound infections who needed antibiotics, 2 had endocarditis and 1 had septicaemia and multiorgan failure. However, interestingly, there were no infections recorded in the liver transplant patients. The infection in the $\mathrm{CM}$ population was leg wound infection in 5 and unknown in 6 . Another important variable demonstrating increased morbidity was the median length of stay, with that in the ASOT group being 6 days (IQR 5.9), whereas in the CM group it was 5 days with an IQR of $4.6(P=0.01)$. The combined major morbidities were overall 11 and $9 \%$ in the in the transplant and CM groups, respectively $(P=0.6)$.

Functional class. More than half of the transplant patients were in NYHA Class III and IV before cardiac surgery, while after the cardiac intervention more than half of the live patients were in Classes I and II. The CM patients were nearly half in Class I and the rest in Class II or III after cardiac surgery. 
Table 3: Time intervals between transplant and cardiac surgery and follow-up periods

\begin{tabular}{|c|c|c|c|c|c|c|}
\hline & $\begin{array}{l}\text { Group } 1 \text { renal } \\
\text { transplant } \\
\text { recipients }(N=30)\end{array}$ & $\begin{array}{l}\text { Group } 2 \text { hepatic } \\
\text { transplant recipients } \\
(N=6)\end{array}$ & $\begin{array}{l}\text { Group } 3 \text { all organ } \\
\text { recipients } \\
(N=36)\end{array}$ & $\begin{array}{l}\text { Group } 4 \text { matched } \\
\text { cohort-non-transplant } \\
(N=104)\end{array}$ & $\begin{array}{l}P \text {-value all } \\
\text { groups }\end{array}$ & $\begin{array}{l}\text { P-value } \\
\text { Group } 3 \\
\text { vs } 4\end{array}$ \\
\hline $\begin{array}{l}\text { Time from most recent } \\
\text { transplant to cardiac surgery } \\
\text { (years) }\end{array}$ & $10.8 \pm 7.4$ & $4.2 \pm 3.0$ & $10.3 \pm 7.2$ & NA & NA & NA \\
\hline $\begin{array}{l}\text { Time from cardiac surgery to } \\
\text { follow-up months median } \\
\text { (inter-quartile) }\end{array}$ & $51.9(24.0-90.6)$ & $21.7(8.8-41.3)$ & $46.3(20.8-84.1)$ & $38.9(14.6-72.3)$ & 0.06 & 0.25 \\
\hline
\end{tabular}

NA: not applicable.

Table 4: Major morbidities

\begin{tabular}{|c|c|c|c|}
\hline Morbidity & $\begin{array}{l}\text { Transplant } \\
\text { Group } 3\end{array}$ & $\begin{array}{l}\text { Case-match } \\
\text { Group } 4\end{array}$ & $P$-value \\
\hline $\begin{array}{l}\text { Length of stay } \\
\text { (median) }\end{array}$ & 6 days (IQR 5.9) & 5 days (IQR 4.6) & 0.01 \\
\hline Return to theatre & $2(5.5 \%)$ & $4(3.8 \%)$ & 0.765 \\
\hline Arrhythmias & $11(30.5 \%)$ & 28 (26.9\%) & 0.515 \\
\hline Pulmonary & $1(2.7 \%)$ & $4(3.8 \%)$ & 1.00 \\
\hline Neurological & $1(2.7 \%)$ & $5(4.08 \%)$ & 1.00 \\
\hline New dialysis & $3(8.3 \%)$ & $1(0.96 \%)$ & 0.049 \\
\hline Infection & $6(16.66 \%)$ & $6(0.42)$ & 0.045 \\
\hline Allograft loss & $0(0 \%)$ & NA & NA \\
\hline
\end{tabular}

\section{Mortality}

There was no 30-day or 'in-hospital' mortality in either group. Late mortality in the transplant group was 8 (22.2\%) (Table 5). Interestingly, all late deaths were in the renal transplant patients, making it 8 of $30(26.6 \%)$ in the renal transplant group, while late mortality in the hepatic transplant patients was $0 / 6(0 \%)$. Infection was the most major cause of late death 5 of 36 (13.88\%), with 2 patients developing endocarditis, 2 developing multiorgan failure due to sepsis and 1 developing mediastinitis. One patient each $(3.33 \%)$ died because of cardiac failure and arrhythmias, while the cause of death in 1 patient could not be ascertained. In contrast, 3 of 104 patients in the CM group died of cardiac causes $(2.88 \%)$. Three patients died of unrelated causes (1 lung cancer, 1 committed suicide, 1 unidentified cause). The total mortality in the cross-matched group was 6 of 104 (6\%) (Table 5). No post-mortem examination results were available in the patients who died.

On multivariate analysis, the predictors of late mortality were increasing age and history of solid organ transplant. Increasing age had HR of 1.1 with $95 \% \mathrm{Cl}$ of $1.04-1.18$ and $P$-value of 0.003 . History of solid organ transplant was found to have HR of $3.44 ; 95 \% \mathrm{Cl}$ of $1.19-9.98$ and a $P$-value of 0.023 .

One of the patients who died was on continuos abdomino peritoneal dialysis, the rest of the patients had functioning allografts and all were on immunosuppression. Of 8 patients who died 2 had undergone CABG, 1 isolated valve replacement and 5 had combined CABG and valve replacement.
Survival was calculated using the Kaplan-Meier survival curves. There was a significant diversion in the survival curves at the end of 10 years between the transplant and the CM cohort outlining the increased mortality of allograft recipients. One-, 2-, 5- and 10-year survivals for ASOT vs CM were $94,88,80,59$ vs 99, 99, 91 and $85 \%$, respectively. Multivariate predictors of mortality were increasing age (HR 1.1, 95\% $\mathrm{Cl} 1.04-1.18 ; P=0.003)$ and solid organ transplantation (HR 3.44, Cl 1.19-9.98; $P=0.023$; Fig. 2).

\section{DISCUSSION}

Continued analysis of current treatment and management strategies predicts the course of the future direction in the modification of treatment and improvement of outcomes and advises on new directions in research funding and planning. This could not be truer than in the investigation of disease processes in the ever-expanding population of allograft recipients.

End-stage renal disease (ESRD) patients have poor life expectancy, but it has improved since the advent of dialysis [4]. Our previous publication highlights that despite dialysis, the mortality rates in ESRD patients are high, 9.99 deaths per 100 patient years in peritoneal dialysis and 7.96 deaths per 100 patient years in haemodialysis patients [5]. Transplantation confers the highest survival benefit among different renal replacement therapies; however, renal allograft recipients still have a high mortality rate compared with population controls.

It was shown that though renal transplant improves the mortality to an impressive 2.3 per 100 patient years, it is still significantly higher than the matched general population [5]. For example, in one European study, the mortality of the recipients of the first renal transplants was 14 times higher than the agematched population without renal failure during the first year after transplantation and was four times higher after this period [6].

The incidence of cardiovascular events in transplant recipients including myocardial infarction was as high as $6.1 \%$ within a month of renal transplant [7]. In addition to the short-term increase in morbidity, cardiovascular events are the most common cause of death in functioning renal transplant recipients. In a study by West et al. [8], it was seen that $17 \%$ of deaths in renal transplant recipients happened because of myocardial infarction, while about $15 \%$ died from arrhythmias. In a more recent study, even the late mortality was ascribed to cardiovascular disease. According to Briggs [9], the most common cause of late mortality after successful renal transplant is cardiovascular disease, accounting for $40-55 \%$ of all deaths. The relative risk of ischaemic cardiac 
Table 5: Mortality and break up of individual causes of mortality in solid organ transplant patients

\begin{tabular}{|c|c|c|c|c|}
\hline & $\begin{array}{l}\text { Group } 1 \text { renal transplant } \\
\text { recipients }(N=30)\end{array}$ & $\begin{array}{l}\text { Group } 2 \text { hepatic transplant } \\
\text { recipients }(N=6)\end{array}$ & $\begin{array}{l}\text { Group } 3 \text { all organ recipients } \\
(N=36)\end{array}$ & $\begin{array}{l}\text { Group } 4 \text { matched cohort- } \\
\text { non-transplant }(N=104)\end{array}$ \\
\hline Follow-up time & $1829 \pm 1186$ & $751 \pm 596$ & $1649 \pm 1176(4.5 \pm 3.2$ years $)$ & $1428 \pm 1173(3.9 \pm 3.2$ years $)$ \\
\hline Deaths & 8 & 0 & $8 / 36=22.2 \%$ & $6 / 104=6 \%$ \\
\hline Cause of death & $\begin{array}{l}\text { Infection } 5 \\
\text { Cardiac } 1 \\
\text { Arrhythmia } 1 \\
\text { Uncertain } 1\end{array}$ & 0 & NA & $\begin{array}{l}\text { Cardiac } 3 \\
\text { Lung cancer } 1 \\
\text { Suicide } 1 \\
\text { Uncertain } 1\end{array}$ \\
\hline
\end{tabular}

NA: not applicable.

There was no mortality in hepatic transplant patients.

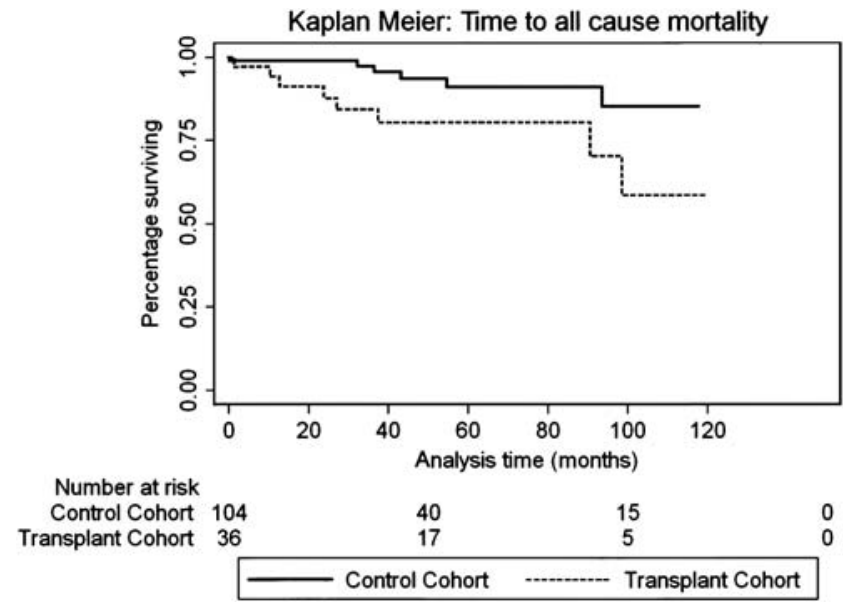

Figure 2: Kaplan-Meier survival estimates: time to all-cause mortality: multivariate predictors of mortality were increasing age (HR 1.1, 95\% Cl 1.04-1.18; $P=0.003$ )and solid organ transplantation (HR 3.44, 95\% Cl 1.19-9.98; $P=0.023$.

events was noted to be 3.07 (95\% $\mathrm{Cl} 1.98-4.53)$ and the relative risk for cardiovascular deaths was $2.56(95 \% \mathrm{Cl}, 1.52-4.05)$ in allograft recipients compared with an age-matched population without transplants [4].

The higher risk profile of these allograft recipients predisposes them to cardiovascular disease primarily because of the preexisting co-morbidities, e.g. hypertension and diabetes. In other patients, hypertension, hyperlipidaemia and hyperhomocysteinemia develop due to renal failure, higher levels of thrombogenic factors in the pretransplant interval, together with higher fluid volume and electrolyte imbalance. Proteinuria and anaemia also increase the risk [10]. The already high-risk profile of this cohort is further exposed to 'transplant pathophysiology', which is far from physiological. Post-transplant immunosuppression (almost always used in conjunction with steroids) causes increase in serum lipids, diabetes mellitus and hypertension and can predispose to coronary artery disease, and despite prevention and treatment, show poor prognosis [5]. Not only the incidence of the coronary artery disease, but also mitral and aortic valve calcification, is increased [11]. Patients with liver transplant, a group without the traditional risk factors for cardiovascular disease (as seen in the renal transplant patients), also have a greater than $10 \%$ incidence of adverse cardiovascular events after hepatic transplant [12]. In hepatic transplant patients, $40 \%$ have dyslipidaemia and $60 \%$ have systolic hypertension. These patients have a higher risk of cardiovascular deaths and ischaemic events than the age and sex-matched population [4].

The dysfunctional organ seems to have been replaced with another hitherto unnamed 'surrogate disease' complex, which consequently translates into an increased incidence of new cardiovascular disease as well as exaggerated progression of existing cardiovascular disease in the transplant patients. Needless to say, the overwhelming burden of cardiac disease in the fastincreasing cohort of allograft recipients requires intervention. Medical therapy, percutaneous intervention and cardiovascular surgery are all treatment options for these patients. Cardiovascular surgery can improve the quality of life, but increased problems with wound healing, infection and allograft failure are concerns of paramount importance. Interestingly, cardiovascular surgery as a process in itself is far from physiological and compounds the problems of existing cardiovascular disease, new cardiovascular disease, transplant pathophysiology and post-transplant immunosuppression due to the deleterious effects of cardiopulmonary bypass. The allograft itself is vulnerable to surgical injury, ischaemia-reperfusion injury and systemic inflammatory response consequent to cardiopulmonary bypass [13].

A study was planned to investigate the complex interplay of the above-mentioned variables on functioning of the allografts both in the perioperative period and in the long-term. The course of cardiovascular disease in post-transplant patients, freedom from cardiovascular symptoms, re-intervention, re-hospitalization and their early, mid- and long-term survivals was studied. This is the first study where outcomes of cardiac surgery in patients with prior solid organ transplants were compared with the $\mathrm{CM}$ population in terms of age, sex and type of cardiac surgery.

Various groups have investigated the cardiac surgical outcomes in transplant recipients from 1984 till recently (Table 6). Most reports have concentrated on renal transplant patients [13], while others have considered only liver transplants [14] and some have included pancreatic transplants as well $[2,15]$. Our study investigated both liver and kidney transplant patients.

Again all the studies including ours are retrospective; however, only one of the studies has compared the outcomes in transplant patients with those of the general cardiac surgical population. The population had not been case-matched and the compared groups were from different time frames [2]. This study incorporates a $\mathrm{CM}$ population in a ratio of $1: 3$ from the same time frames. This study, therefore, provides a level playing field 
Table 6: Critical comparison of previous studies of cardiac surgery in transplant recipients

\begin{tabular}{|c|c|c|c|c|c|c|}
\hline Investigators & Year & Number of patients/transplant type & Procedures & Perioperative mortality & Long-term survival & Other important points \\
\hline Bolman et al. [20] & 1984 & 14 Renal & CABG, valve & $14 \%$ Operative & 79\% Mean 13 months & \\
\hline De Meyer et al. [18] & 1991 & 13 Renal & CABG & $11 \%$ & $85 \%: 3$ years & \\
\hline Dresler et al. [21] & 1997 & 45 Renal & CABG, valve & $8.8 \%$ Operative & $85 \%: 5$ years & \\
\hline Mitruka et al. [16] & 1997 & 40 Renal, hepatic and thoracic & $\begin{array}{l}\text { CABG, valve, great vessel, } \\
\text { pericardiectomy TMR }\end{array}$ & $3 \%$ (30 days) & $\begin{array}{l}\text { Mean } 22 \text { months }(1-90) \\
\text { Total } 86 \% \\
\text { Renal } 80 \% \\
\text { Hepatic } 94 \% \\
\text { Thoracic } 100 \%\end{array}$ & \\
\hline Prabhakar et al. [14] & 1998 & 15 Liver & CABG, valve & No 30-day mortality & & $\begin{array}{l}\text { Follow-up short; } \\
\text { Two late deaths: cardiac and infection; } \\
\text { Repeat interventions: } 2 / 15 \\
\text { Cardiac follow-up - subjective: doing well! and } \\
\text { not doing well!! }\end{array}$ \\
\hline Ferguson et al. [24] & 1999 & 45 Renal & CABG, PTCA & & $78 \%-3$ year & $\begin{array}{l}\text { Includes renal transplant after the } \\
\text { revascularization as well }\end{array}$ \\
\hline Reddy et al. [22] & 2002 & 26 Renal & CABG, valve & $7.7 \%$ & $69 \%$ Med 38 months & \\
\hline Ono et al. [15] & 2002 & 55 (9 with pancreas and kidney) & CABG, valve & $5.5 \%$ & $72.2 \%$ (kidney) & \\
\hline Herzog et al. [19] & 2004 & 1100 Renal & CABG & $\begin{array}{l}\text { IMA: } 5.0 \% \\
\text { No IMA: } 9.4 \%\end{array}$ & $\begin{array}{l}\text { With IMA: } 82.7 \% \\
\text { Without IMA: } 74.4 \%\end{array}$ & \\
\hline Deb et al. [23] & 2006 & 47 Renal and hepatic & $C A B G$, valve & $2 \%$ & $\begin{array}{l}\text { Renal } \\
\quad 1 \text { year: } 97 \pm 3 \% \\
5 \text { year: } 82 \pm 8 \% \\
\text { Hepatic } \\
1 \text { year: } 77 \pm 12 \% \\
5 \text { year: } 69 \pm 13 \%\end{array}$ & $\begin{array}{l}\text { Time from transplant to surgery: liver and renal } \\
\text { Mentioned most common causes for renal: } \\
\text { diabetes/glomerulonephritis } \\
\text { Hepatic: sclerosing cholangitis }\end{array}$ \\
\hline Zhang et al. [13] & 2006 & 57 Renal & CABG, valve & $5.3 \%$ & 3 year: $71 \%$ & Allograft failure requiring dialysis $28.6 \%$ \\
\hline John et al. [2] & 2007 & 74 Kidney/kidney-pancreas & CABG, valve & $1.4 \%$ & Not studied & $\begin{array}{l}\text { No follow-up } \\
32 \% \text { postoperative kidney dysfunction } \\
\text { Study and matched cohorts-different time frames } \\
\text { (1995-2005) (2000-2005) } \\
\text { Only 30-day mortality } \\
\text { Follow-up is only morbidities } \\
\text { CCF/emergency surgery/long CPB/PVD/and } \\
\text { decreased creatinine clearance: predictors of } \\
\text { mortality } \\
\text { Prophylactic stress steroids to all } \\
\text { More haemodialysis transplant group }\end{array}$ \\
\hline Rahmanian et al. [3] & 2009 & 29 Renal & $C A B G$, valve & $3.4 \%$ & $\begin{array}{l}1 \text { year: } 89 \pm 6 \% \\
5 \text { year: } 50 \pm 14 \%\end{array}$ & $\begin{array}{l}\text { Temporary allograft dysfunction described as } \\
\text { more than } 30 \% \text { increase in creatinine and bun }\end{array}$ \\
\hline Sharma et al. [17] & 2010 & 1335 Renal & Valve & $14 \%$ & $\begin{array}{l}2 \text { year } \\
\text { Tissue: } 61.5 \% \\
\text { Non-tissue: } 59.5 \%\end{array}$ & $\begin{array}{l}11.4 \% \text { mortality: tissue } \\
15 \% \text { non-tissue valve }\end{array}$ \\
\hline
\end{tabular}


for the comparison between the transplant and the nontransplant population undergoing cardiac surgery. Our study has included all types of cardiac, pericardiac and great vessel surgery like Mitruka et al. [16]. Some of the groups have restricted the study to only valves [17] or only CABG $[18,19]$. However, most groups have studied the combined population of CABG and valve patients [13-16, 20-23].

In our series, there was no perioperative mortality in either of the groups. This is in contrast to other studies where the perioperative mortality varied from 1.4 [2], 2 [23], 3 [16], 5 [15] and 8.8 [21] to $14 \%$ [1]. However, Prabhakar's group [14] has also reported no early mortality. We ascribe this to be the result of close cooperation between the cardiac surgical teams, the renal and hepatic transplant physicians, the anaesthetists and the intensivists, who are available round the clock because of the excellent logistics of a tertiary-care hospital facility.

In our series, the mean age of the patient population was $56 \pm 11$ years in both the groups with a range of 31.02-74.06 years. Increasing age was found to be an independent predictor of late mortality in our series. It is in consonance with the findings of Sharma et al. [17]. However, in other studies, the independent predictors of mortality were perioperative renal status, mitral valve disease and left ventricular dysfunction [13], cardiopulmonary bypass $>180 \mathrm{~min}$, congestive cardiac failure and emergency heart surgery [2]. Again, Sharma et al. [17] found combined mitral and aortic valve surgery and ESRD caused by diabetes mellitus to be independently associated with increased mortality.

The late mortality in our series was $22.2 \%$ in the transplant group. Interestingly, all late deaths were in renal transplant patients making it $26.6 \%$ for the renal transplant group. This is consistent with the world literature and also consistent with our expectation of high mortality given the increased burden of comorbidities in the transplant population. Interestingly, 62.5\% of all late deaths had infective aetiology, which can be ascribed to the immunosuppression and the concomitant systemic steroid therapy. Surprisingly, no incidence of lymphoma was observed contrary to the expectations in people with long-term immunosuppression, though 7 of the 36 transplant recipients reported incidence of recurrent skin cancers. Here, it would be pertinent to point out that either post-mortem examinations were not performed in the patients who died or the results were not available. Though the cause of death was assumed to be known, there could be fallacies in the actual cause of death, which could skew the results. Interestingly, no reference has been made in the relevant world literature about post-mortem examination in the cause of death.

The long-term survival in our series was $94 \%$ for the transplant group vs $99 \%$ for the CM group at the end of 1 year. It was 88 vs $99 \%$ at 2 years, 80 vs $91 \%$ at 5 years and 59 vs $85 \%$ at the end of 10 years for the transplant and $\mathrm{CM}$ groups, respectively. However, it has to be remembered that the follow-up in the CM population was less than the mandatory $95 \%$ mark that is important for the accurate comparison of experimental vs control groups. The late survival is marginally better than that reported in the literature $[3,13,16,23]$ and may be attributed to small sample size or better follow-up care by a multidisciplinary team in a tertiary hospital as highlighted earlier. One multivariate analysis again predicted transplant to be an independent risk factor for mid-term and late mortalities. It is interesting to note that there was no early or late mortality in the liver transplant patients. No early mortality in liver transplant patients has also been reported by Prabhakar et al. [14], but late survival has only been reported to be $69 \pm 13 \%$ by Deb et al. [23].

Seven of the 30 renal transplant patients had new renal failure (19.4\%), 3 of these 7 needed dialysis, however, none of them contributed to mortality. These findings correlate with other published reports [2]. This is a pointer to the fact that transplanted organs can manage the perioperative stress. Similar opinions have been voiced by others [16]. There was no acute rejection or allograft loss in our transplant population either perioperatively or in late follow-up. It is pertinent to point out here that our group does not alter the immunosuppression regimen. This is in contrast with other publications where the incidence of allograft loss has been from 15\% [23] in renal transplant and 15\% in hepatic transplant [23], 23\% [16] to 30\% [13]. This can be ascribed to our practice of keeping the high perfusion pressure during cardiopulmonary bypass as unit policy. There was transient elevation of liver enzymes and creatinine levels in both the liver and kidney transplant cohorts. The levels of both showed a trend towards normalization or towards preoperative levels at discharge. This finding has allowed us to deduce that daily renal and liver functions are not required unless the immediate postoperative functions are extremely disturbed or otherwise clinically indicated. A similar opinion has been published by others [14]. The immunosuppression was continued even in failed transplant patients on the premise that it will prevent acute rejection-a process that is still possible, despite failed allograft. It also prevents the development of anti human leucocyte antigen antibodies, which will affect the acceptance of allograft should the patient need a repeat transplant [2].

Infection was the most common complication. $16.66 \%$ as expected with the burden of immunosuppression and steroid administration. However, we consider that prolonged use of antibiotics is not required and routine prophylaxis is adequate. This is reflected in the fact that 3 patients had minor infections in the early postoperative period, while 3 had major infection late in the postcardiac surgery follow-up and died due to sepsis. Similar results of around 15\% have been reported by others [16].

The length of stay in the transplant cohort is a median of 6 days (IQR 5.9), which can be reasonably expected. It is significantly more than that of the matched population statistically, but is shorter than that reported in another study by Ono et al., who reported a length of stay of $8.5 \pm 6.9$ (3-42 days), we attribute the shorter length of stay to reduced the incidence of postoperative morbidities.

\section{CONCLUSION}

This study provides a comparative analysis between patients undergoing cardiac surgery after solid organ transplants and a matched group of patients without transplant. Cardiac surgery can be performed in solid organ transplant recipients with early morbidity and mortality comparable with the cross-matched population. This needs modifications in conduct of cardiopulmonary bypass and management of immunosuppression with a dedicated team of transplant physicians. Solid organ transplant emerging as a predictor of late death has never been reported previously. Long-term survival is poor. Infection remains the major cause of late death. We attribute our encouraging results to the multidisciplinary team approach of surgeons, anaesthetists, transplant physicians and intensivists. The key to long-term 
survival is regular follow-up, prevention of infection and early treatment with urgent referral to a facility with suitable logistics. Consequently, patients should be informed in detail during the consent process about the possibility of repeated visits to an appropriately equipped facility. Resources and manpower should be allocated to meet these needs. Post-mortem examinations should be encouraged in all in-hospital mortalities.

Conflict of interest: none declared.

\section{REFERENCES}

[1] Johnston SD, Morris JK, Cramb R, Gunson BK, Neuberger J. Cardiovascular morbidity and mortality after orthotropic liver transplantation. Transplantation 2002;73:901-6.

[2] John R, Lietz K, Huddleston S, Matas A, Liao K, Shumway S et al. Perioperative outcomes of cardiac surgery in kidney and kidney-pancreas transplant recipients. J Thorac Cardiovasc Surg 2007;133:1212-9.

[3] Rahmanian PB, Adams DH, Castillo JG, Silvay G, Filsoufi F. Excellent results of cardiac surgery in patients with previous kidney transplantation. J Cardiothorac Vasc Anesth 2009;23:8-13.

[4] Collins AJ, Foley RN, Herzog C, Chavers BM, Gilbertson D, Ishani A et al. Excerpts from US Renal data system 2009 report. Am J Kidney Dis 2010; 55(Suppl. 1):S1-420, A (6-7).

[5] Johnson DW, Dent H, Hawley CM, McDonald SP, Rosman F, Brown F et al. Association of dialysis modality and cardiovascular mortality in incident dialysis patients. Clin J Am Soc Nephrol 2009;4:1620-8.

[6] Arend SM, Mallat MJ, Westendorp RJ, van der Woude FJ, van Es LA. Patient survival after renal transplantation; more than 25 years follow-up. Nephrol Dial Transplant 1997;12:1672.

[7] Humar A, Kerr SR, Ramcharan T, Gillingham KJ, Matas AJ. Perioperative cardiac morbidity in kidney transplant recipients: incidence and risk factors. Clin Transplant 2001;15:154-8.

[8] West M, Sutherland DER, Matas AJ. Kidney transplant recipients who die with functioning grafts: serum creatinine level and cause of death. Transplantation 1996;15:1029-32.

[9] Briggs JD. Causes of death after renal transplantation [editorial]. Nephrol Dial Transplant 2001;16:1545-9.

[10] Levey AS, Beto JA, Coronado BE, Eknoyan G, Foley N, Kasike BL et al. Controlling the epidemic of cardiovascular disease in chronic renal failure: what do we know? What do we need to learn? Where do we go from here? Am J Kidney Dis 1998;32:853-906.

[11] Goodman WG, Golden J, Kuizon BD, Yoon C, Gales B, Sider D et al. Coronary artery calcification in young adults with adults with end-stage renal disease who are undergoing dialysis. N Engl J Med 2000;342:1478-83.

[12] Abbasoglu O, Levy MF. Cardiovascular events following liver transplantation. N Dev Transplant Med 1995;2:9-10.

[13] Zhang L, Garcia JM, Hill PC, Haile E, Light JA, Corso PJ. Cardiac surgery in renal transplant recipients: experience from Washington Hospital Center. Ann Thorac Surg 2006;81:1379-84.

[14] Prabhakar G, Testa G, Abbasoglu O, Jeyarajah DR, Goldstein RM, Levy MF et al. The safety of cardiac operations in the liver transplant recipient. Ann Thorac Surg 1998;65:106.

[15] Ono M, Wolf RK, Angouras DC, Brown DA, Goldstein AH, Michler RE. Short- and long-term results of open heart surgery in patients with abdominal solid organ transplant. Eur J Cardiothorac Surg 2002;21: 1061-72.

[16] Mitruka SN, Griffith BP, Kormos RL, Hattler BG, Pigula FA, Shapiro R et al. Cardiac operations in solid-organ transplant recipients. Ann Thorac Surg 1997;64:1270-8.

[17] Sharma A, Gilbertson DT, Herzog CA. Survival of kidney transplantation patients in the United States after cardiac valve replacement. Circulation 2010;121:2733-9.

[18] De Meyer M, Wyns W, Dion R, Khoury G, Pirson Y, van Ypersele De Strihou C. Myocardial revascularization in patients on renal replacement therapy. Clin Nephrol 1991;36:147-51.

[19] Herzog CA, Ma JZ, Collins AJ. Long-term outcome of renal transplant recipients in the United States after coronary revascularization procedures. Circulation 2004;109:2866-71.

[20] Bolman RM, Anderson RW, Molina JE, Schwartz JS, Levine B, Simmons $\mathrm{RL}$ et al. Cardiac operations in patients with functioning renal allografts. J Thorac Cardiovasc Surg 1984;88:537-43.

[21] Dresler C, Uthoff K, Wahlers T, Kliem V, Schäfers J, Oldhafer K et al. Open heart operations after renal transplantation. Ann Thorac Surg 1997;63:143-6.

[22] Reddy VS, Chen AC, Johnson HK, Peirson RN, Christian KJ, Drinkwater DC Jr et al. Cardiac surgery after renal transplantation. Am Surg 2002;68: 154-8.

[23] Deb SJ, Mullany CJ, Kamath PS, Dearani JA, Daly RC, Orszulak TA et al. Cardiac surgery in kidney and liver transplant recipients. Mayo Clin Proc 2006;81:917-22.

[24] Ferguson ER, Hudson SL, Diethelm AG, Pacifico AD, Dean LS, Holman WL. Outcome after myocardial revascularization and renal transplantation: a 25-year single-institution experience. Ann Surg 1999;230: 232-41. 